Guo-zheng Quan*, Jin Liu, An Mao, Bo Liu and Jin-sheng Zhang

\title{
A Characterization for the Hot Flow Behaviors of As-extruded 7050 Aluminum Alloy
}

\begin{abstract}
The deep understanding of flow behaviors of as-extruded 7050 aluminum alloy significantly contributes to the accuracy simulation for its various plastic forming processes. In order to obtain the improved Arrhenius-type equation with variable parameters for this alloy, a series of compression tests were performed at temperatures of $573 \mathrm{~K}, 623 \mathrm{~K}, 673 \mathrm{~K}, 723 \mathrm{~K}$ and strain rates of $0.01 \mathrm{~s}^{-1}, 0.1 \mathrm{~s}^{-1}, 1 \mathrm{~s}^{-1}, 10 \mathrm{~s}^{-1}$ with a height reduction of $60 \%$ on Gleeble-1500 thermo-mechanical simulator. It is obvious that strain rate, strain and temperature all have a significant effect on the hot flow behaviors, and the true stress-true strain curves indicate three types after the peak value: decreasing gradually to a steady state with sustaining DRX softening till a balance with work hardening, decreasing continuously with sustaining increasing DRX softening beyond work hardening and maintaining higher stress level after the peak value with a balance between work hardening and DRV softening. Based on the experimental data, the improved Arrheniustype constitutive model was established to predict the high temperature flow stress of as-extruded 7050 aluminum alloy. The accuracy and reliability of the improved Arrhenius-type model were further evaluated in terms of the correlation coefficient $(R)$, here 0.98428 , the average absolute relative error (AARE), here 3.5\%. The results indicate that the improved Arrhenius-type constitutive model presents a good predictable ability.
\end{abstract}

Keywords: flow behavior, constitutive model, 7050 aluminum alloy

PACS. 81. material science

DOI 10.1515/htmp-2014-0108

Received June 22, 2014; accepted October 6, 2014

*Corresponding author: Guo-zheng Quan, School of Material Science and Engineering, Chongqing University, Chongqing 400044 China, E-mail: quangz3000@sina.com

Jin Liu: E-mail: 1976395432@qq.com, An Mao:

E-mail: 316088924@qq.com, School of Material Science and

Engineering, Chongqing University, Chongqing 400044, China

Bo Liu: E-mail: liubo1@changan.com.cn, Jin-sheng Zhang:

E-mail: zhangjs2@changan.com.cn, Chongqing Changan

Automobile Co., Ltd., Chongqing 400023, China

\section{Introduction}

7050 alloy is one of $7 x x x$ series $(\mathrm{Al}-\mathrm{Zn}-\mathrm{Mg}-\mathrm{Cu})$ aluminum alloys, which has attractive mechanical and excellent combination of physical characteristics that make it a good choice for many aerospace applications [1]. The hot flow behaviors of aluminum alloys during a hot forming process are often complex due to the co-existence and interaction of hardening and softening mechanisms which are both significantly sensitive to temperature, strain and strain rate $[2,3]$. The deep understanding of hot flow behaviors of 7050 alloy contributes to the design in various forming processes of the alloy such as hot rolling, forging, extrusion, etc. [4, 5]. How to characterize and even model the hot flow pattern of the alloy is a significant issue ensuring the accuracy of simulation analysis as well as the kinetics of metallurgical transformation. Developing a constitutive equation of 7050 alloy can not only characterize the stress-strain data collected from isothermal hot compression tests but also predict the data which are out of the experiment conditions. And this equation can be embedded in the finite element analysis software to get the accurate calculation of the thermoplastic deformation for this alloy [1, 4].

The response of hot flow behaviors of 7050 alloy under elevated temperatures and strain rates is highly nonlinear; and many factors affecting flow stress are also nonlinear, which decreases the accuracy of the flow stress predicted by the regression methods and limits their applicable range. In recent years, much attention is paid to the prediction of flow stress based on the constitutive equations resulting from experiments, meanwhile many constitutive models were proposed [1, 3-5]. The research results of Zener and Hollomon show that the internal strain rate of the material is controlled by heat activation process during high-temperature plastic deformation. Thus, the factor of temperature compensation may be raised to express the relationship between strain rate and the temperature, known as parameter $Z$ [6]. Then Zener and Hollomon introduce the parameter $Z$ into the Arrhenius equation to establish an Arrhenius-type constitutive model. The traditional Arrhenius-type constitutive model only predicts the flow stress at a fixed strain, which cannot satisfy the need of numerical simulations 
in various hot forming processes because of the lack of strain effect on flow stress. By taking the effect of strain into account, a developed hyperbolic-Sine Arrhenius equation has been proposed to predict the flow stress of various metals or alloys. Lin et al. [4] revised the traditional Arrhenius type equation by introducing straindependent parameters (including material constants $n$, $\alpha, \beta, A$ and $Q$ ) into the constitutive equation. The revised model was proved successfully in predicting the flow stress of 42CrMo steel [7]. The high accuracy of such model was also verified in Ti-Al-Cr-V alloy by $\mathrm{Pu}$ et al. [8], Mg-Al4-Z1 alloy by Slooff et al. [9], 2124-T851 aluminum alloy by Lin et al. [10] and A356 aluminum alloy by Haghdadi et al. [11]. Up to now, few attentions have been paid to model the hot compression behaviors of 7050 alloy with such equation.

In the present work, the object of this study is to characterize the influence of strain, strain rate and temperature on the flow behaviors of as-extruded 7050 aluminum alloy. Toward this end, a series of isothermal hot compression tests have been carried out at temperatures of $573 \mathrm{~K}, 623 \mathrm{~K}, 673 \mathrm{~K}$ and $723 \mathrm{~K}$, and strain rates of $0.01 \mathrm{~s}^{-1}$, $0.1 \mathrm{~s}^{-1}, 1 \mathrm{~s}^{-1}$ and $10 \mathrm{~s}^{-1}$. The measured stress-strain data obtained from compression tests were used to develop the hyperbolic sine constitutive equation describing the relationships of flow stress, strain rate and temperature by considering the proper compensation of strain. And then an improved Arrhenius-type constitutive equation was derived to predict the hot flow behaviors for as-extruded 7050 aluminum alloy. Finally, the developed constitutive equation was validated by the correlation coefficient $(R)$, and average absolute relative error (AARE).

\section{Materials and procedures}

The chemical compositions of as-extruded 7050 aluminum alloy used in the study were (wt.\%): $0.07 \mathrm{Fe}, 5.90$ Zn, $0.01 \mathrm{Cr}, 2.10 \mathrm{Mg}, 2.10 \mathrm{Cu}, 0.11 \mathrm{Zr}, 0.03 \mathrm{Si}, 0.03 \mathrm{Ti}$, and the balance of Al. The following experimental procedures are according to ASTM Standard: E209-00. The hot compression tests were performed on a computer-controlled, servo-hydraulic Gleeble-1500 thermo-simulation machine. It can be programmed to simulate both thermal and mechanical processes in a wide range of hot deformation conditions. The specimen geometry with a diameter of $10 \mathrm{~mm}$ and height of $12 \mathrm{~mm}$ meets the approval of Gleeble-1500 machine, and 17 such cylindrical specimens for compression tests were machined by electrical discharge wire-cutting. On the computer-controlled, servohydraulic Gleeble-1500 machine, each specimen was resistance-heated to deformation temperature at a heating rate of $10 \mathrm{~K} / \mathrm{s}$ and held for $180 \mathrm{~s}$ to decrease the anisotropy in flow deformation behavior. Sixteen specimens were compressed at four different temperatures of $573 \mathrm{~K}, 623 \mathrm{~K}, 673 \mathrm{~K}$ and $723 \mathrm{~K}$, and four different strain rates of $0.01 \mathrm{~s}^{-1}, 0.1 \mathrm{~s}^{-1}, 1 \mathrm{~s}^{-1}$ and $10 \mathrm{~s}^{-1}$. After each compression, the deformed specimen was immediately quenched in water to retain the deformed microstructure at elevated temperature.

During a compressing process, the variations of stress and strain were monitored continuously by a personal computer equipped with an automatic data acquisition system. The true stress-strain relationships were derived from the nominal stress-strain data collected according to the following formula: $\varepsilon_{T}=-\ln \left(1-\varepsilon_{N}\right)$, $\sigma_{T}=-\sigma_{N}\left(1-\varepsilon_{N}\right)$ [12], where $\sigma_{T}$ is the true stress, $\sigma_{N}$ the nominal stress, $\varepsilon_{T}$ the true strain and $\varepsilon_{N}$ the nominal strain.

\section{Results and discussion}

\section{Flow stress curves}

The continuous stress-strain curves of as-extruded 7050 aluminum alloy under different temperatures and strain rates are illustrated in Figure 1(a)-(d). It is obvious that strain rate and temperature have significant effect on flow stress. Comparing these curves with one another, it is found that at a fixed strain rate, the flow stress level decreases markedly with increasing temperature and at a fixed temperature, the flow stress level generally increases with increasing strain rate due to an increase of dislocation density and the dislocation multiplication rate. Therefore, it can be summarized that increasing strain rate or decreasing deformation temperature makes the flow stress level increase, in other words, it inhibits the occurrence of softening mechanisms such as DRX and DRV, which makes the deformed metals exhibit more work hardening (WH). This is due to the fact that higher strain rate provides shorter time for the energy accumulation and lower temperature provides lower mobilities at boundaries, which inhibits the nucleation and growth of dynamically recrystallized grains and dislocation annihilation [13-15]. From stress-strain curves, it can be seen that the stress evolution with strain exhibits three distinct stages [16]. At the first stage, WH predominates and causes dislocations to polygonize into stable subgrains; therefore flow stress exhibits a rapid increase to a critical value with increasing strain at the 


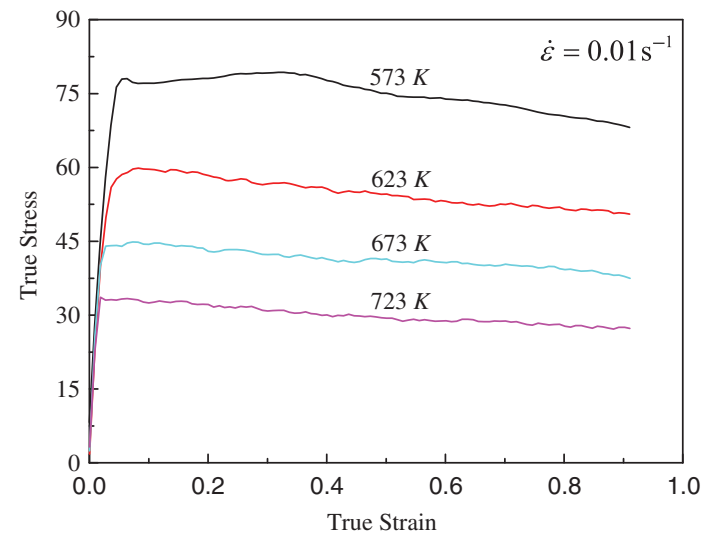

(a)

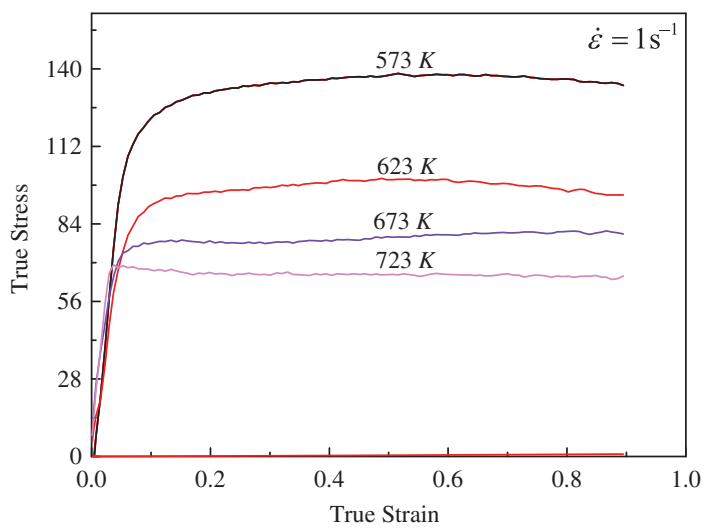

(c)

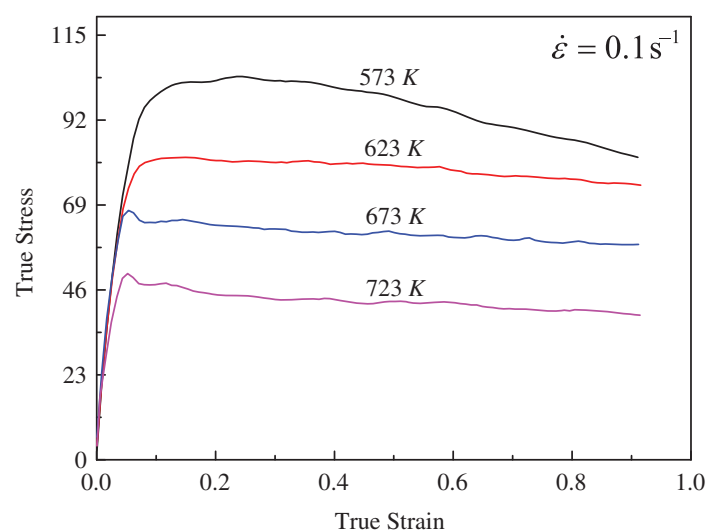

(b)

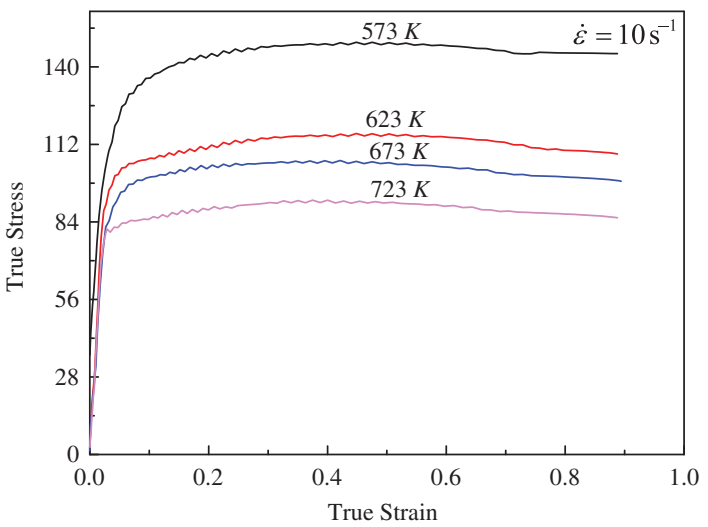

(d)

Figure 1 True stress-strain curves of as-extruded 7050 aluminum alloy at different strain rates and temperatures (a) $0.01 \mathrm{~s}^{-1}, 573-723 \mathrm{~K},(\mathrm{~b})$ $0.1 \mathrm{~s}^{-1}, 573-723 \mathrm{~K}$, (c) $1 \mathrm{~s}^{-1}, 573-723 \mathrm{~K}$, (d) $10 \mathrm{~s}^{-1}, 573-723 \mathrm{~K}$

stage, meanwhile the stored energy in grain boundaries originates from a large difference in dislocation density within subgrains or grains and grows rapidly to DRX activation energy. When the critical driving force is attained, new grains are nucleated along the grain boundaries, deformation bands and dislocations, resulting in equiaxed DRX grains. At the second stage, flow stress exhibits a smaller and smaller increase until a peak value or an inflection of WH rate, which shows that the thermal softening due to DRX and DRV becomes more and more predominant, then it exceeds WH. At the third stage, three types of curve variation tendency can be generalized as following: decreasing gradually to a steady state with DRX softening (573-723 K \& $0.01 \mathrm{~s}^{-1}, 623-723 \mathrm{~K} \& 0.1 \mathrm{~s}^{-1}$ ), and decreasing continuously with significant DRX soften-

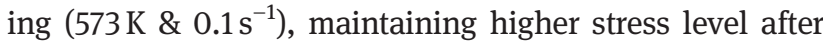
the peak value with DRV softening $\left(573-723 \mathrm{~K} \& 1 \mathrm{~s}^{-1}\right.$,

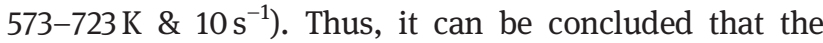
typical form of flow curve with DRX softening, including a single peak followed by a steady state flow as a plateau and continuously decreasing, is more recognizable at higher temperatures and lower strain rates. This is due to the fact that at higher strain rates and lower temperatures, the higher WH rate slows down the rate of DRX softening, and both the peak stress and the onset of steady-state flow are therefore shifted to higher strain levels.

\section{Constitutive equations for flow stress of 7050 aluminum alloy}

\section{Determination of the material constants for the constitutive equation at strain of 0.1}

The constitutive equations are developed to determine deformation behavior at different temperatures and different strain rates. The most widely used is Arrhenius equation which represents the relationships between the strain rate, flow stress and temperature. The effects of the temperatures and strain rate on the deformation behavior can be represented by Zener-Hollomon parameter, $Z$, is an exponent-type equation $[17,18]$. 


$$
\begin{gathered}
Z=\dot{\varepsilon} \exp (Q / R T) \\
\dot{\varepsilon}=A F \exp (-Q / R T) \\
F(\sigma)= \begin{cases}\sigma^{n^{\prime}} & \alpha \sigma<0.8 \\
\exp (\beta / \sigma) & \alpha \sigma>1.2 \\
{[\sin h(\alpha \sigma)]^{n}} & \text { for all } \sigma\end{cases}
\end{gathered}
$$

(1) Meanwhile value of $1 / \beta$ can be considered as the average value of all the lines' slopes of Figure 2(b), and $\beta=0.126991 \mathrm{MPa}^{-1}$. Then, $\alpha=\beta / n^{\prime}=0.012972$.

For all stress levels (including both low and high stress levels), eq. (2) can be represented as following:

$$
\dot{\varepsilon}=A[\sin (\alpha \sigma)]^{n} \exp (-Q / R T)
$$

where $\dot{\varepsilon}$ is the strain rate $\left(\mathrm{s}^{-1}\right), R$ is the universal gas constant $\left(8.31 \mathrm{~J} \mathrm{~mol}^{-1} \mathrm{~K}^{-1}\right), T$ is the absolute temperature $(K), Q$ is the activation energy of hot deformation $\left(\mathrm{kJ} \mathrm{mol}^{-1}\right), \sigma$ is the flow stress (MPa). $A, n^{\prime}, \beta, \alpha$ and $n$ are the material constants, and $\alpha=\beta / n^{\prime}$.

The followed process is taking the deformation strain of 0.1 as an example to demonstrate the evaluation procedure of material constants. For the low stress level $(\alpha \sigma<0.8)$ and high stress level $(\alpha \sigma>1.2)$, substitute the value of $F(\sigma)$ into eq. (2), which gives

$$
\begin{gathered}
\dot{\varepsilon}=B \sigma^{n^{\prime}} \\
\dot{\varepsilon}=B^{\prime} \exp (B \sigma)
\end{gathered}
$$

where $B$ and $B^{\prime}$ are the material constants which are dependent on deformation temperatures.

Taking the logarithm of both sides of eqs (3) and (4), respectively, gives,

$$
\begin{gathered}
\ln \sigma=\frac{1}{n^{\prime}} \ln \dot{\varepsilon}-\frac{1}{\beta} \ln B \\
\sigma=\frac{1}{\beta} \ln \dot{\varepsilon}-\frac{1}{\beta} \ln B^{\prime}
\end{gathered}
$$

Then, substituting the values of the flow stress and corresponding strain rate under the strain of 0.1 into the logarithm eqs (5) and (6), which give the relationship between the flow stress and strain rate, as shown in Figure 2. The average value of all the lines' slopes from Figure 2(a) is equal to the inverse of $n^{\prime}$ value, thus, $n^{\prime}=9.766 \mathrm{MPa}^{-1}$.
Taking the natural logarithm at both ends of eq. (7), eq. (8) follows:

$$
\ln [\sin h(\alpha \sigma)]=\frac{1}{n} \ln \dot{\varepsilon}+\frac{Q}{n R T}-\frac{1}{n} \ln A
$$

Therefore, the value of $n$ can be obtained from the slopes of the lines in the $\ln [\sin h(\alpha \sigma)]-\ln \dot{\varepsilon}$ plot, as illustrated in Figure 3(a). And the value of $n$ was carried out as 7.223.

For a given strain rate, there is a linear relationship between $\ln [\sin h(\alpha \sigma)]$ and $1 / T$, eq. (8) can be written as:

$$
Q=R n\{d[\ln \sin (\alpha \sigma)] / d(1 / T)\}
$$

So the value of $Q$ can be calculated from the slopes in the plot of $\ln [\sin h(\alpha \sigma)]-1 / T$, as shown in Figure 3(b). The mean value of all the slopes is accepted as $Q /(R n)$ value, furthermore $Q$ value for $\dot{\varepsilon}=0.1$ is obtained as $145 \mathrm{~kJ} . \mathrm{mol}^{-1}$. By substituting the value of $n, Q, \alpha$ to eq. (8), subsequently, $\ln A$ at a certain particular strain 0.1 can be obtained and its value was computed to be 24.67795. So the value of $A$ is $5.22 \times 10^{10} s^{-1}$. Substituting $n, Q, \alpha$ and $A$ into eq. (7) gives the relationships between $\dot{\varepsilon}, T$ and $\sigma$ as following:

$$
\begin{aligned}
\dot{\varepsilon}= & 5.22 \times 10^{10}\left[\sin h(0.012972 \sigma)^{7.223}\right] \\
& \exp \left[-\left(145 \times 10^{3}\right) / 8.31 T\right]
\end{aligned}
$$

Substituting the $Z$ parameter $Z=\dot{\varepsilon} \exp (Q / R T)$ into eq. (2), thus the flow stress can be expressed as eq. (11):

$$
\sigma=\frac{1}{\alpha} \ln \left\{(Z / A)^{1 / n}+\left[(Z / A)^{2 / n}+1\right]^{1 / 2}\right\}
$$

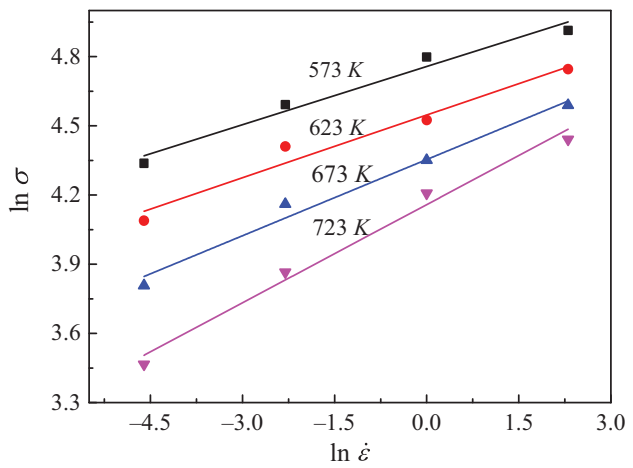

(a)

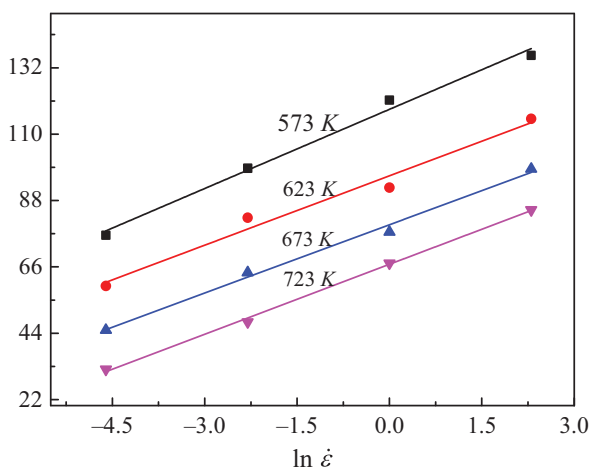

(b)

Figure 2 Relationships between: $(a) \ln \sigma-\ln \dot{\varepsilon},(b) \sigma-\ln \dot{\varepsilon}$ 


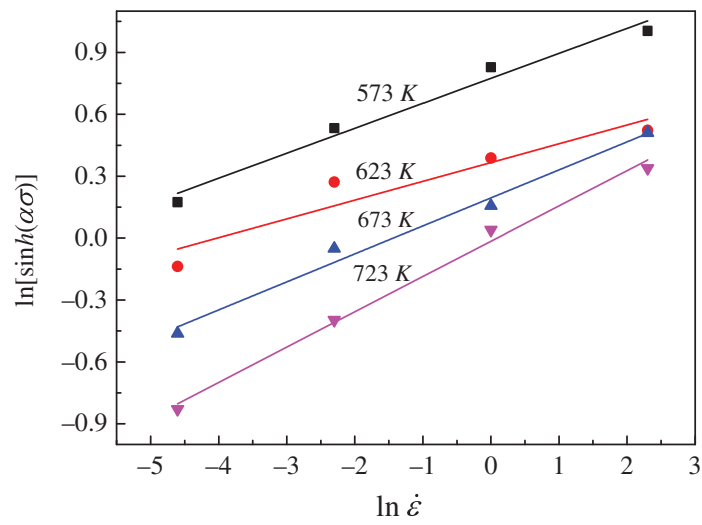

(a)

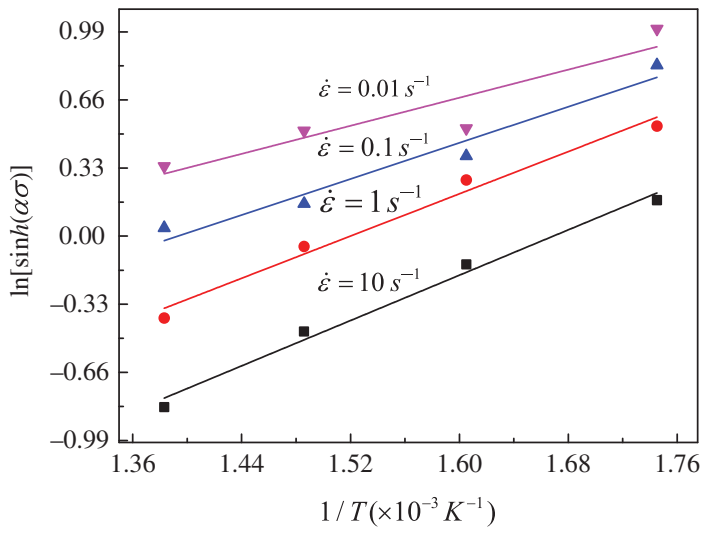

(b)

Figure 3 (a) $\ln [\sin h(\alpha \sigma)]-\ln \dot{\varepsilon}$, (b) $\ln [\sin h(\alpha \sigma)]-1 / T$

Here, substituting $Z=\dot{\varepsilon} \exp \left(145 \times 10^{3} / \mathrm{RT}\right)$ and $A=5.22 \times$ $10^{10} \mathrm{~s}^{-1}$ into eq. (11), the constitutive equation for flow behavior of as-extruded 7050 aluminum alloy can be expressed as eq. (12).

$$
\begin{aligned}
\sigma= & 77.089 \ln \left\{\left\{\frac{\dot{\varepsilon} \exp \left[\frac{\left(145 \times 10^{3}\right)}{8.31 T}\right]}{\left(5.22 \times 10^{10}\right)}\right\}^{1 / 7.5565}\right. \\
& \left.+\left\{\left\{\frac{\dot{\varepsilon} \exp \left[\frac{\left.145 \times 10^{3}\right)}{8.31 T}\right]}{\left(5.22 \times 10^{10}\right)}\right\}^{2 / 7.5565}+1\right\}^{1 / 2}\right\}
\end{aligned}
$$

\section{Construction of constitutive equation in the strain range of $0-0.9$}

The above is taking the strain of 0.1 as an example, so the similar method processes can be used to determine the material constants $(\alpha, n, Q$ and $\ln A)$ under other deformation strains with the range of $0-0.9$ and with the interval of 0.1. Because the influences of the strain on flow stresses at elevated temperatures were insignificant, the relationships between $Q, \ln A, n, \alpha$ and true strain $\varepsilon$ for as-extruded 7050 aluminum alloy were polynomial fitted by the compensation of strain, as shown in eq. (13). The polynomial fitted results of $Q, \ln A, n, \alpha$ of asextruded 7050 aluminum alloy are provided in Table 1. The variation of material constants is shown in Figure 4.

$$
\begin{aligned}
Q= & j(\varepsilon)=B_{0}+B_{1} \varepsilon+B_{2} \varepsilon^{2}+B_{3} \varepsilon^{3}+B_{4} \varepsilon^{4}+B_{5} \varepsilon^{5} \\
n= & h(\varepsilon)=C_{0}+C_{1} \varepsilon+C_{2} \varepsilon^{2}+C_{3} \varepsilon^{3}+C_{4} \varepsilon^{4}+C_{5} \varepsilon^{5} \\
\ln A= & \ln f(\varepsilon)=D_{0}+D_{1} \varepsilon+D_{2} \varepsilon^{2}+D_{3} \varepsilon^{3} \\
& +D_{4} \varepsilon^{4}+D_{5} \varepsilon^{5}+D_{6} \varepsilon^{6}+D_{7} \varepsilon^{7} \\
\alpha= & g(\varepsilon)=E_{0}+E_{1} \varepsilon+E_{2} \varepsilon^{2}+E_{3} \varepsilon^{3}+E_{4} \varepsilon^{4}+E_{5} \varepsilon^{5}
\end{aligned}
$$

Substituting $\alpha, n, Q$ and $A$ in eq. (13) into eq. (7) gives the relationships between $\varepsilon, T$ and $\sigma$ as eq. (14).

$$
\dot{\varepsilon}=f(\varepsilon)\{\sin [g(\varepsilon) \sigma]\}^{h(\varepsilon)} \times \exp (j(\varepsilon) / 8.31 T)
$$

Thus, $Z=\dot{\varepsilon} \exp (j(\varepsilon) / R T)$. Furthermore, the constitutive equation for flow behavior of as-extruded 7050 aluminum alloy in a wide strain range of $0-0.9$ can be expressed as eq. (15).

Table 1 Polynomial fitting results of $Q, n, \ln A$ and $\alpha$ of 7050 aluminum alloy

\begin{tabular}{rrrrrrrr}
\hline & $\mathbf{Q}$ & & $\mathbf{n}$ & & $\ln \mathbf{A}$ & $\mathbf{\alpha}$ \\
\hline$B_{5}$ & $-9.66 \mathrm{E}+05$ & $C_{5}$ & -20.446 & $D_{8}$ & 24.67795 & $E_{5}$ & -0.01914 \\
$B_{4}$ & $2.55 \mathrm{E}+06$ & $C_{4}$ & 64.007 & $D_{7}$ & 24.55715 & $E_{4}$ & 0.050608 \\
$B_{3}$ & $-2.44 \mathrm{E}+06$ & $C_{3}$ & -79.289 & $D_{6}$ & 23.60286 & $E_{3}$ & -0.05656 \\
$B_{2}$ & $1.03 \mathrm{E}+06$ & $C_{2}$ & 49.621 & $D_{5}$ & 23.45177 & $E_{2}$ & 0.035459 \\
$B_{1}$ & $-2.09 \mathrm{E}+05$ & $C_{1}$ & -17.028 & $D_{4}$ & 23.42845 & $E_{1}$ & -0.01034 \\
$B_{0}$ & $1.58 \mathrm{E}+05$ & $C_{0}$ & 8.4962 & $D_{3}$ & 22.4249 & $E_{0}$ & 0.013699 \\
& & & & $D_{2}$ & 20.76575 & & \\
& & & & $D_{1}$ & 21.85679 & & \\
\end{tabular}




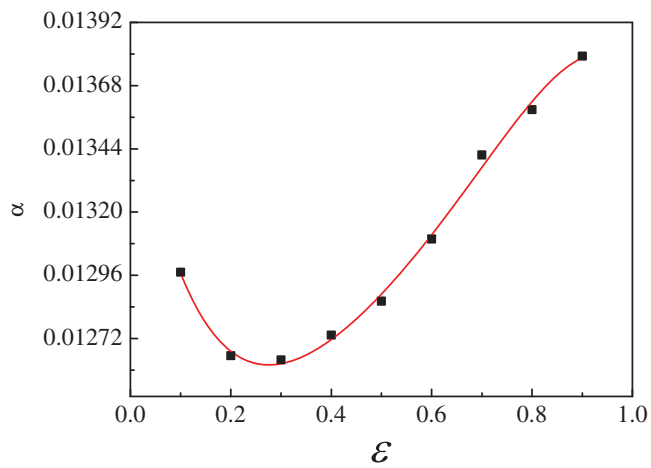

(a)

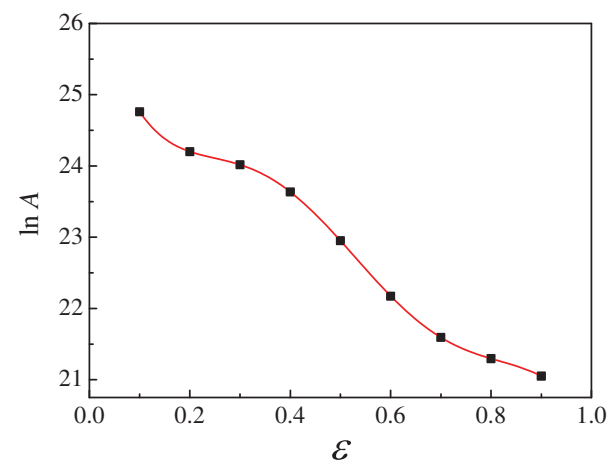

(c)

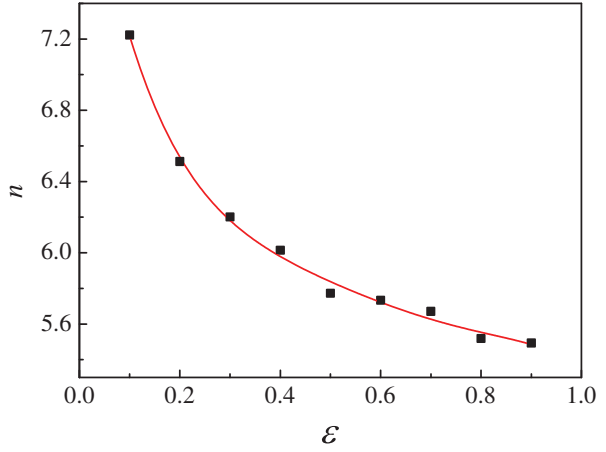

(b)

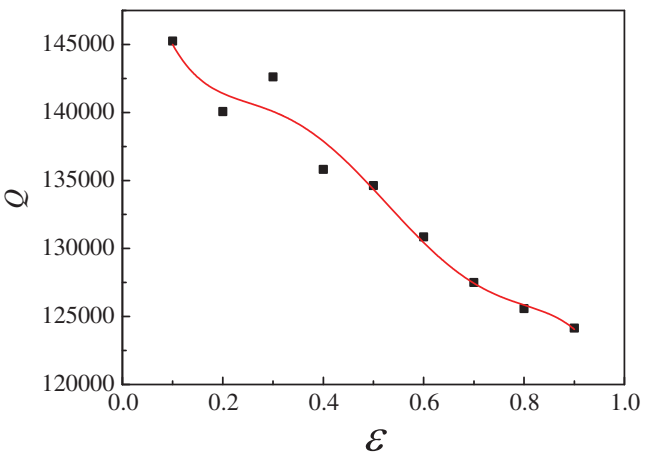

(d)

Figure 4 Relationships between (a) $Q$, (b) $n$, (c) $\alpha$, (d) $\ln A$ and true strain by polynomial fit of 7050 aluminum alloy

$$
\begin{aligned}
\sigma= & \frac{1}{g(\varepsilon)} \ln \left\{\left(\frac{\dot{\varepsilon} \exp (j(\varepsilon) / 8.31 T)}{f(\varepsilon)}\right)^{\frac{1}{h(\varepsilon)}}\right. \\
& \left.+\left[\left(\frac{\dot{\varepsilon} \exp (j(\varepsilon) / 8.31 T)}{f(\varepsilon)}\right)^{\frac{2}{h(\varepsilon)}}+1\right]^{\frac{1}{2}}\right\}
\end{aligned}
$$

where $f(\varepsilon), g(\varepsilon), h(\varepsilon)$ and $j(\varepsilon)$ are the polynomial functions of $A, \alpha, n$ and $Q$ at different true strains, and their expressions are as eq. (13) and Table 1.

\section{Availability of the improved Arrhenius model}

In order to verify the above-developed constitutive equation of 7050 aluminum alloy at different temperatures and different strain rates, a comparison between the experimental and predicted results was carried out. Figure 5 shows the comparisons between experimental stressstrain data and the calculated values at four different temperatures under strain rates of $0.01 \mathrm{~s}^{-1}, 0.1 \mathrm{~s}^{-1}, 1 \mathrm{~s}^{-1}$ and $10 \mathrm{~s}^{-1}$. Figure 6 shows the correlation degree between the experimental and predicted data $(R=0.98428$,
$A A R E=3.5 \%$ ), which reflects the excellent predictability of the improved Arrhenius model.

\section{Conclusions}

The flow behavior of as-extruded 7050 aluminum alloy was investigated using hot compression tests in the temperature range of $573-723 \mathrm{~K}$ and the strain rate range of $0.01-10 \mathrm{~s}^{-1}$ in the present study. Some conclusions were concluded as following:

(1) The true stress-true strain curves show three different types: decreasing gradually to a steady state with sustaining DRX softening mechanisms till a balance is obtained with $\mathrm{WH}$, decreasing continuously with sustaining increasing DRX softening mechanisms beyond $\mathrm{WH}$ and maintaining higher stress level after the peak value with a balance between WH and DRV softening.

(2) The adaptability of the Improved Arrhenius model with variable parameters was evaluated by correlation coefficient $(R)$, here 0.98428 , and average absolute relative error $(A A R E)$, here $3.5 \%$. 


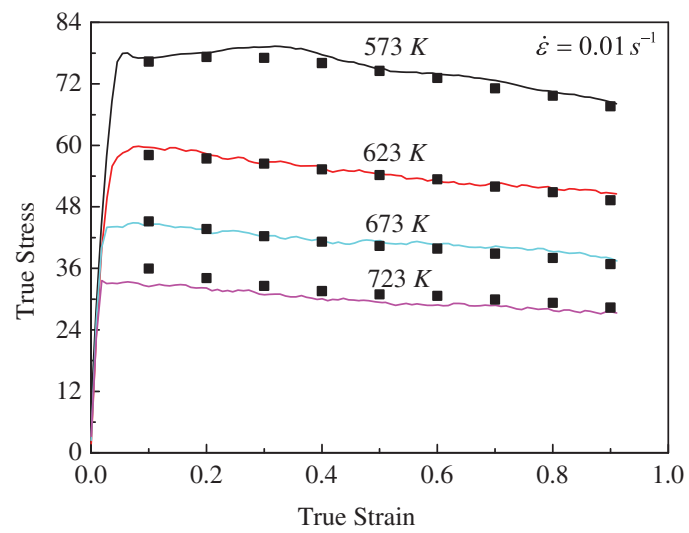

(a)

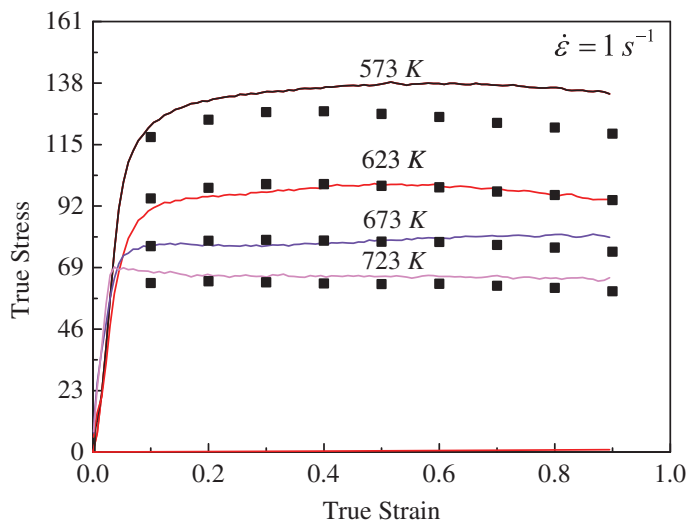

(c)

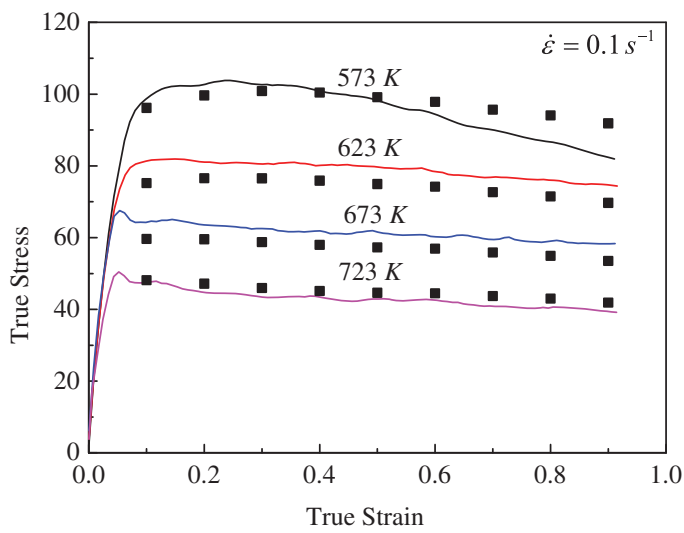

(b)

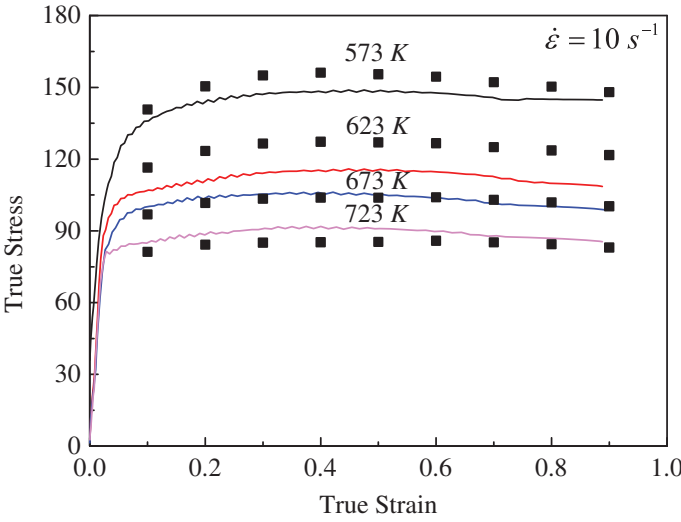

(d)

Figure 5 The comparisons of experimental stress-strain data with the calculated values for the four different temperatures under strain rates of (a) $0.01 \mathrm{~s}^{-1}$, (b) $0.1 \mathrm{~s}^{-1}$, (c) $1 \mathrm{~s}^{-1}$ and (d) $10 \mathrm{~s}^{-1}$

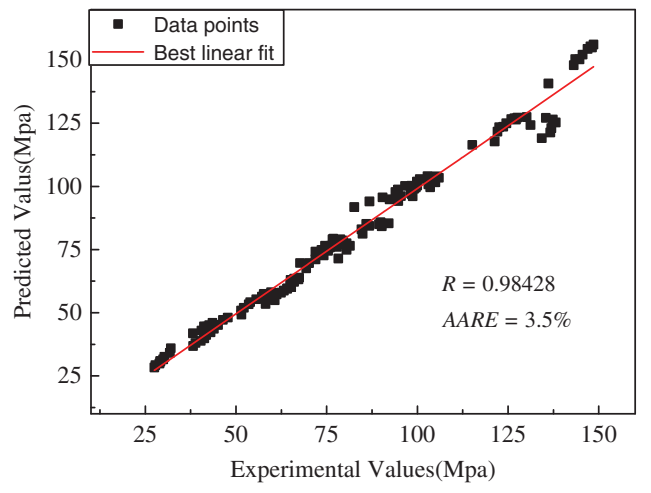

Figure 6 Correlation between experimental and predicted flow stress

(3) The strain effects on the material constants such as $\alpha, n, \ln A$ and $Q$ were characterized by high-order polynomials.

Acknowledgments: This work was supported by Fundamental Research Funds for the Central Universities (CDJZR13130084).

\section{References}

1. Quan GZ, Liu KW, Zhou J, Nonferr T. A characterization for the dynamic recrystallization kinetics of as-extruded 7075 aluminum alloy based on true stress-strain curves. Metal Soc 2009;19:537-41.

2. Quan G-Z, Mao Y-P, Yu C-T, Lv W-Q, Zhou J. The Flow Behavior Modeling of As-extruded 3Cr20Ni10W2 Austenitic Heat-resistant Alloy at Elevated Temperatures Considering the Effect of Strain. Mater Res 2014;17:451-60.

3. Quan G-Z, Wu D-S, Luo G-C, Xia Y-F, Zhou J, Liu Q, et al. Dynamic recrystallization kinetics in $\alpha$ phase of as-cast Ti-6Al-2Zr-1Mo-1V alloy during compression at different temperatures and strain rates. Mater Sci Eng A 2014;589:23-33.

4. Lin YC, Chen MS, Zhang J. Modeling of flow stress of $40 \mathrm{CrMo}$ steel under hot compression. Mater Sci Eng A 2009;499:88-92.

5. Quan G-Z, Li G-S, Wang Y, Lv W-Q, Yu C-T, Zhou J. A Characterization for the Flow Behavior of As-Extruded 7075 Aluminum Alloy by the Improved Arrhenius Model With Variable Parameters. Mater Res 2013;16:19-27.

6. Zener C, Hollomon JH. Effect of strain rate upon plastic flow of steel. J Appl Phys 1944;15:22-32.

7. Quan G, Tong Y, Luo G, Zhou J. A characterization for the flow behavior of 42CrMo steel. Comp Mater Sci 2010;50:167-71. 
8. Pu ZJ, Wu KH, Shi J, Zou D. Development of constitutive relationships for the hot deformation of boron microalloying TiAl-Cr-V alloys. Mater Sci Eng A 1995;192-193:780-7.

9. Slooff FA, Zhou J, Duszczyk J, Katgerman L. Constitutive analysis of wrought magnesium alloy Mg-Al4-Zn1. Scripta Mater 2007;57:759-62.

10. Lin YC, Xia Y-C, Chen X-M, Chen M-S. Constitutive descriptions for hot compressed 2124-T851 aluminum alloy over a wide range of temperature and strain rate. Comp Mater Sci 2010;50:227-33.

11. Haghdadi A, Zarei-Hanzaki HR. The flow behavior modeling of cast A356 aluminum alloy at elevated temperatures considering the effect of strain. Abedi Mater Sci Eng A 2012;535:252-7.

12. Samantaray D, Mandal S, Bhaduri AK. A critical comparison of various data processing methods in simple uni-axial compression testing. Mater Des 2011;32:2797-802.
13. Momeni A, Dehghani K, Keshmiri H, Ebrahimi GR. Mater Sci Eng A 2010;527:1605-11.

14. Lin YC, Chen MS, Zhong J. Constitutive modeling for elevated temperature flow behavior of $42 \mathrm{CrMo}$ steel. Comp Mater Sci 2008;42:470-7.

15. Quan GZ, Li GS, Chen T, Wang YX, Zhang YW, Zhou J. Dynamic recrystallization kinetics of $42 \mathrm{CrMo}$ steel during compression at different temperatures and strain rates. Mater Sci Eng A 2011;528:4643-51.

16. Dehghan-Manshadi A, Barnett MR, Hodgson PD. Recrystallization in AISI 304austenitic stainless steel during and after hot deformation. Mater Sci Eng A 2008;485:664-72.

17. Zener C, Hollomon $\mathrm{H}$. Effect of strain-rate upon the plastic flow of steel. J Appl Phys 1944;15:22-7.

18. Shi H, McLaren AJ, Sellars CM, Shahani R, Bolingbroke R. Constitutive equation for high temperature flow stress of aluminum alloys. Mater Sci Tech 1997;13:210-16. 